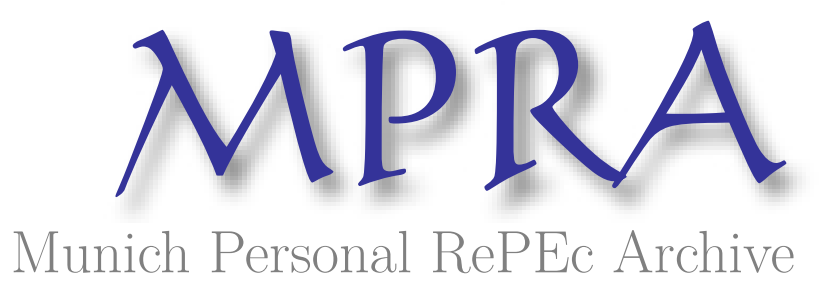

\title{
Executive Stock Option Pricing in China under Stochastic Volatility
}

Chong, Terence Tai Leung and Ding, Yue and Li, Yong

The Chinese University of Hong Kong and Nanjing University, The Chinese University of Hong Kong, Renmin University of China

27 February 2015

Online at https://mpra.ub.uni-muenchen.de/63397/

MPRA Paper No. 63397, posted 07 Apr 2015 07:35 UTC 


\title{
Executive Stock Option Pricing in China under Stochastic Volatility
}

\author{
Terence Tai Leung $\mathrm{CHONG}^{1}$ \\ Executive Director, Institute of Global Economics and Finance and Associate Professor, \\ Department of Economics, The Chinese University of Hong Kong, Hong Kong \\ and \\ Siyuan Chair Professor, Department of International Economics and Trade, Nanjing University, \\ Nanjing, China

\section{Yue DING} \\ Ph.D. graduate, Department of Economics, The Chinese University of Hong \\ Kong, Hong Kong
}

\begin{abstract}
Yong $\mathrm{LI}^{2}$
Associate Professor, Hanqing Advanced Institute of Economics and Finance, Renmin University of China, Beijing, China
\end{abstract}

$27 / 2 / 15$

\footnotetext{
${ }^{1}$ Corresponding Author: Terence Tai-Leung Chong, Department of Economics, The Chinese University of Hong Kong, Shatin, N.T., Hong Kong. E-mail: chong2064@cuhk.edu.hk. Phone. 852-3948193. Fax: 852-26035805.

Homepage: http://www.cuhk.edu.hk/eco/staff/tlchong/tlchong3.htm.

${ }^{2} \mathrm{Li}$ acknowledges the financial support from the Natural Science Foundation of China (No.71271221). We thank Prof. Robert I. Webb for constructive and insightful suggestions and the seminar participants at the 2014 International Conference on Futures and Derivative Markets in Shanghai for helpful comments.
} 


\begin{abstract}
In this paper, on the basis of stochastic volatility (SV) models, we extend the approach of option pricing for executive stock options (ESOs) under FAS 123. Based on this extension, a sample of Chinese listed companies' ESOs are priced. We analyze the effect of the some important financial variables on the implementation of ESOs. It is found that in China, firms with higher market risk and larger size are likely to have a higher ESO proportion in their executive incentive plans. The effects of the book-to market ratio, stock price volatility, executive shareholding proportion, and the leverage ratio are also examined.
\end{abstract}

Keywords: Bayesian analysis; Executive stock options; FAS 123; Option pricing; SV models. 


\section{Introduction}

As a long-term incentive mechanism, executive stock options (ESOs) outperform other incentives in stimulating managers, lowering agency costs, integrating human resources, and improving the overall performance of a company. ESOs are now widely adopted in the United States (U.S.). We present the aspects that differentiate the ESO from the European call option (ECO) in Table 1.

The 1972 Accounting Principles Board (APB) Opinion No. 25, known as "accounting for stock issued to employees" (APB 25), is adopted as the primary regulatory accounting treatment of ESO cost in the U.S. The method used for the valuation of APB 25 is the intrinsic value method, but this leaves out the time value of the stock options. Consequently, it significantly underestimates the value of stock options. Due to the numerous defects in APB 25, in 1995, the Financial Accounting Standards Board (FASB) issued the Statement of Financial Accounting Standards No. 123 Notice "Accounting treatment of stock-based compensation expense" (FAS 123), later revised in 2004. Instead of the intrinsic value method, this statement encourages companies to apply the fair value method, or the Black-Scholes (BS) method, to measure ESO costs (Rubinstein, 1995; Hull \& White, 2004).

Unfortunately, when the standard BS model is applied for ESO pricing, the value of the ESOs is often overestimated. Hence, under the FAS 123 guidelines, Hull \& White $(2002,2003$, 2004) proposed the adjusted binary tree model. In this pricing approach, an important assumption is that the asset return volatility is constant over time. However, in the literature, it is well documented that volatility is time-varying and exhibits stylized volatility clustering (Engel, 1982; Taylor, 1994). Engle (1982) first proposed the autoregressive conditional heteroskedasticity $(\mathrm{ARCH})$ model to estimate the temporal dependency of volatility. Bollerslev 
(1986) extended the ARCH model by developing the generalized ARCH (GARCH) model. Taylor (1986) introduced the so-called stochastic volatility (SV) model in which volatility is an unobserved variable that follows an AR(1) process. Taylor (1994) and Shephard (1996) compared ARCH-type models and the SV model to show that the SV model can be better in fitting financial data. Duan (1995) applied the GARCH model to the option pricing models. Li \& Huang (2004) developed a new GARCH approach for ESO pricing in Asia. In this paper, rather than using the GARCH model and the Asian option pricing approach, we extend Hull \& White's (2002, 2003, 2004) pricing using the adjusted binary tree model incorporated in the SV framework, given that the SV model may be better in modeling time-varying volatility.

In addition to examining pricing approaches, some empirical studies examine the factors which influence the implementation of ESOs. For example, using the data from 792 large U.S. companies from 1984 to 1991, Yermack (1995) found that firms facing liquidity problems, difficulties in supervision but having better growth prospects tended to adopt ESOs. Mehran (1995) showed that firms with more external directors and managers with fewer shares implemented more ESOs. Joskow et al. (1996) found that in most regulated industries, such as the electric power industry, fewer ESOs were implemented as incentive measures. Choe (2003) confirmed that corporate investment risk, financial risk, and stock market risk could affect the incentive effect of ESOs by influencing the number of options being exercised. Chen \& Lee (2010) studied the dynamic effects of growth opportunities and risks on ESOs and found that high risk and high growth opportunities increased the number of ESO grants - an effect that lasted for two to three years after the implementation of ESOs.

This paper examines the firm characteristics that lead to the implementation of ESOs in China. The ESOs of more than 80 Chinese listed companies are priced using the ESO pricing 
method with the SV model under FAS 123. Our results show that the market risk and firm size has a significant effect on the total grant value of ESOs. Firms with higher market risk and larger size are likely to increase the proportion of ESOs in their executive incentive plans. The effects of the book-to-market ratio, the stock price volatility, the executive shareholding proportion and the leverage ratio are also examined.

The rest of the paper is organized as follows. Section 2 presents the Bayesian approach for SV models. Section 3 presents the ESO pricing method under the FAS 123 framework based on SV models. Section 4 reports the empirical results. Section 5 concludes the paper.

\section{Stochastic Volatility Models}

The basic form of the SV model can be expressed as follows:

$$
\begin{gathered}
y_{t}=\exp \left(\theta_{t} / 2\right) \varepsilon_{t}, \varepsilon_{t} \sim \text { i.i.dN }(0,1), t=1,2, \ldots, n \\
\theta_{t}=\mu+\phi\left(\theta_{t-1}-\mu\right)+\eta_{t}, \eta_{t} \sim \text { i.i.dN }\left(0, \sigma^{2}\right), t=1,2, \ldots, n
\end{gathered}
$$

where $y_{t}$ is the demeaned return at time $t$, and $\theta_{t}$ is the log volatility. The error terms $\eta_{t}$ and $\varepsilon_{t}$ are uncorrelated and unobservable. For $\left.\right|^{\phi} \mid<1$, the SV model is covariance stationary. The parameter $\sigma$ measures the standard error of the volatility.

The analysis of SV models is not a trivial task as the likelihood function does not have any analytical form. Various estimation approaches have been proposed, such as quasi-maximum likelihood inference, efficient method of moments, and Bayesian inference. In recent years, due to the advancements made in Markov chain Monte Carlo (MCMC) methods, Bayesian analysis of SV models has gained prominence in the literature (Jacquier et al., 1994; Kim et al., 1998; Meyer \& Yu, 2000). The idea of MCMC is to acquire samples by constructing a Markov chain 
with stationary distribution $\pi(x)$. Based on these random samples, it is possible to conduct Bayesian statistical inference.

In the SV model, the unobservable variables are $\mu, \phi, \sigma$, and the logarithmic volatility series $\left\{\theta_{t}\right\}$. The joint probability density function of the unobservable variables is given by:

$$
\begin{aligned}
& \pi\left(\mu, \phi, \sigma, \theta_{0: n}\right)=\pi(\mu, \phi, \sigma) \pi\left(\theta_{0} \mid \mu, \phi, \sigma\right) \prod_{i=1}^{n} \pi\left(\theta_{t} \mid \theta_{t-1}, \mu, \phi, \sigma\right) \\
& =\pi(\mu) \pi(\phi) \pi(\sigma) \pi\left(\theta_{0} \mid \mu, \phi, \sigma\right) \prod_{i=1}^{n} \pi\left(\theta_{t} \mid \theta_{t-1}, \mu, \phi, \sigma\right)
\end{aligned}
$$

where $\pi(\mu), \pi(\phi), \pi(\sigma)$ are, respectively, prior distributions for the parameters of $\mu, \phi, \sigma$. According to Bayes' theorem, the unobserved joint posterior density function is proportional to the complete likelihood function as follows:

$$
\pi\left(\mu, \phi, \sigma, \theta_{0: n} \mid y_{0: n}\right) \propto \pi\left(\mu, \phi, \sigma, \theta_{0: n}\right) \pi\left(y \mid \mu, \phi, \sigma, \theta_{0: n}\right) .
$$

MCMC techniques, such as the Gibbs sampler and Metropolis-Hastings (MH) sampler, can provide a mechanism for drawing samples from this posterior distribution, constructing a Markov chain with the same stationary distribution and posterior distribution. When the Markov chain converges, the simulated random samples can be regarded as effective samples drawn from the posterior distribution. The Gibbs sampler process for posterior drawing can be summarized as follows:

(1) Set the initial state point $\psi^{(0)}=\left(\theta_{0: n}^{(0)}, \mu^{(0)}, \phi^{(0)}, \sigma^{(0)}\right)$.

(2) Draw $\theta_{0: n}^{(1)}$ from the full conditional posterior distribution $\pi\left(\theta_{0: n} \mid \theta_{0: n}^{(0)}, \mu^{(0)}, \phi^{(0)}, \sigma^{(0)}\right)$.

(3) Replace $\theta_{0: n}^{(0)}$ with $\theta_{0: n}^{(1)}$, draw $\mu^{(1)}$ from the full conditional posterior distribution $\pi\left(\mu \mid \theta_{0: n}^{(1)}, \mu^{(0)}, \phi^{(0)}, \sigma^{(0)}\right)$. 
(4) Draw $\phi^{(1)}$ the full conditional posterior distribution $\pi\left(\phi \mid \theta_{0: n}^{(1)}, \mu^{(1)}, \sigma^{(0)}, \phi^{(0)}\right)$

(5) Draw $\sigma^{(1)}$ the full conditional posterior distribution $\pi\left(\sigma \mid \theta_{0: n}^{(1)}, \mu^{(1)}, \sigma^{(0)}, \phi^{(1)}\right)$.

The above process completes the first round of iterative sampling. After a sufficient burn-in period, the Gibbs sequence converges to a stationary distribution that is independent of the initial value, which is the target posterior distribution, $\pi\left(\mu, \phi, \sigma, \theta_{0: n} \mid y_{0: n}\right)$.

After discarding the burn-in samples, we can collect a series of random samples from the Gibbs output, which can be regarded as effectively random observations from the joint posterior distribution, $\pi\left(\mu, \phi, \sigma, \theta_{0: n} \mid y_{0: n}\right)$. Let $\theta=\theta_{0: n},\left\{\theta^{(j)}, j=1,2, \cdots, J\right\}$ be these effective random observations drawn from the posterior distribution. Bayesian statistical inference can be performed on the basis of these random observations. For example, Bayesian estimates and the corresponding standard errors of $\theta$ can easily be obtained through the corresponding sample mean and the variance of the observations generated given by:

$$
\hat{\theta}=\frac{1}{J} \sum_{j=1}^{J} \theta^{(j)}, \quad \hat{\operatorname{Var}}(\theta \mid y)=\frac{1}{J-1} \sum\left(\theta^{(j)}-\hat{\theta}\right)\left(\theta^{(j)}-\hat{\theta}\right)^{T}
$$

In practice, Bayesian inference for SV models can be implemented via a user-friendly and freely available software package, WinBUGS (Spiegelhalter et al., 2003). Meyer \& Yu (2000) have illustrated the ease of using Bayesian analysis in SV models. After analyzing the SV models using WinBUGS, we can predict the future volatility of financial assets. From Equation (1), the implied volatility $\theta_{t}$ follows the Gaussian AR (1) process with the persistent parameter $\phi$. We substitute $\theta_{t}, \mu, \phi_{\text {into Equation (1) to predict }} \theta_{t+1}$ and use historical volatility as volatility at time t. After predicting the volatility of stock returns with the SV model, the predicted value is 
substituted in the Hull \& White $(2002,2003,2004)$ ESO pricing methods to price the stock options.

\section{ESO Pricing Method under the FAS 123 Framework}

As the standard BS model always overestimates the ESO value, under the FAS 123 guidelines, Hull \& White $(2002,2003,2004)$ proposed the adjusted binary tree model. Managers tend to exercise ESOs early for maximum return or risk diversification as ESOs are non-tradable. Generally, it is assumed that the managers can voluntarily exercise ESOs in advance when the stock market price is $M$ times the strike price so that the ESO life expectancy can be estimated. Hence, it differs from the ordinary binary tree model, in which the option term equals the last exercisable deadline.

Managers may exercise ESOs after the vesting period. Furthermore, because the expected life of ESOs is correlated with the stock market, the assumption of a constant ESO life expectancy in the ordinary binary tree may not hold. Hence, the inclusion of the manager turnover rate is important in our model because it reflects the probability of managers leaving during the vesting period. Jennergren \& Naslund (1993) analyzed the effect of the manager turnover rate on option pricing, assuming that the turnover rate follows the Poisson process. Foster, et al. (1993) estimated the effect of different turnover rates on option price. Cuny \& Jorion (1995) argued that the manager turnover rate should decline as the stock price increases. As ESOs have the characteristics of U.S. options, this paper applies the binary tree model with the turnover rate adjustment.

Assume that the managers voluntarily exercise their ESOs early, when the stock market price is $M$ times the strike price, and let $\mathrm{K}$ denote the strike price of the option, $v$ the vesting period, 
$e_{1}$ the turnover rate of managers during the vesting period, $e_{2}$ the turnover rate of managers after the vesting period, and $w_{1}, w_{2}$ the continuous composite turnover rates, where $w_{2}^{*}=\ln \left(1+e_{2}\right)$ and $w_{1}^{*}=\ln \left(1+e_{1}\right)$ respectively. Then, following Hull \& White $(2002,2003,2004)$, ESOs can be priced as follows:

$$
\begin{aligned}
& \text { when } 0 \leq i \leq N-1, \\
& \text { if } i \delta t>v \text { and } S_{i, j}>K M, f_{i, j}=S_{i, j}-K . \\
& \text { If } i \delta t>v \text { and } S_{i, j}<K M, \\
& f_{i, j}=\left(1-w_{2}^{*} \delta t\right) e^{-r \delta t}\left[p f_{i+1, j+1}+(1-p) f_{i+1, j}\right]+w_{2}^{*} \delta t \operatorname{Max}\left(S_{i, j}-K, 0\right) .
\end{aligned}
$$

When $i \delta t<v, f_{i, j} e^{-r \delta t}\left[p f_{i+1, j+1}+(1-p) f_{i+1, j}\right]$.

The option value is $f_{0,0}$.

Simultaneously, the ESO life expectancy can be calculated. ${ }_{i, j}$ is defined as the expected life of the ESO when the stock price is $S_{i, j}$ at time $i \delta t$, and $L_{N, j}=0$ :

$$
\begin{aligned}
& \text { when } 0 \leq i \leq N-1, \\
& \text { if } i \delta t>v \text { and } S_{i, j}>K M, L_{i, j}=0 . \\
& \text { If } i \delta t>v \text { and } S_{i, j}<K M, L_{i, j}=\left(1-w_{2}^{*} \delta t\right)\left[p L_{i+1, j+1}+(1-p) L_{i+1, j}+\delta t\right] . \\
& \text { When } i \delta t<v, L_{i, j}=p L_{i+1, j+1}+(1-p) L_{i+1, j}+\delta t .
\end{aligned}
$$

Then, the option price is adjusted by the turnover rate, that is, multiplied by $\left(1-w_{1}\right)^{v}$, so that the final ESO cost is $f_{0,0}\left(1-w_{1}\right)^{v}$. Finally, to obtain the total value of the ESOs, the cost must also be multiplied by the grant number. 


\section{Empirical Results}

On December 31, 2005, the China Securities Regulatory Commission introduced the "Equity Incentive Regulatory Guidance for Listed Companies." Since then, a total of 146 listed companies have reported having equity incentive plans. In May 2008, the Commission issued the "Memorandum of Equity Incentive," requesting that public issues and ESOs should not be conducted simultaneously. Since 2008 , a total of 54 companies, or $37 \%$ of companies in total, have stopped ESOs.

In this paper, we select data on 125 listed companies from the Guotaian (GTA) database, excluding companies with missing data. A total of 83 companies are employed to conduct the empirical research. There are 5, 3, 4, 17, 37, and 16 ESO plans implemented in 2006, 2008, 2009, 2010, 2011, and 2012, respectively. The vesting period ranges from one to four years and the life expectancy ranges from four to ten years.

Due to the non-tradability and vesting period of ESOs, those of the Chinese listed companies are priced using the ESO pricing method under FAS 123, which is based on the SV model. The daily closing price starts from the announcement date of the incentive program to August 8, 2012. Data are drawn from the GTA database. We calculate the demeaned return as $y_{t}=\ln \left(S_{t} / S_{t-1}\right)-\frac{1}{n} \sum_{t=1}^{n} \ln \left(S_{t} / S_{t-1}\right)$, where $S_{t}$ is the closing price on day $t$.

To undertake the Bayesian analysis, we have to assign the prior distribution for SV models.

Following Meyer \& Yu (2000), the prior distributions of parameters $\mu, \phi, \sigma$, and $\theta_{0}$ are specified as follows: 


$$
\begin{aligned}
& \phi_{1 \sim \operatorname{Be}(20,1.5)} \\
& \mu \sim N(0,100) \\
& \sigma^{-2} \sim \operatorname{Gamma}(2.5,0.025)
\end{aligned}
$$

where $\phi=2 \phi_{1}-1$ because the range of $\phi$ is limited to $(-1,1)$ for stationarity.

Using the WinBUGS software, we run 50,000 Gibbs iterations discarding the first 10,000 draws as burn-in samples. The remaining 40,000 iterations are collected as effectively random observations from the posterior distribution. The Bayesian statistical inference can be established based on the random observations. After obtaining the Bayesian estimation, the SV model is applied to forecast the daily expected volatility of the stock.

In the ESO pricing model under the FAS 123 framework, the parameters include the following: share price, strike price, maximum exercise time, life expectancy of ESOs, vesting period, risk-free interest rate, expected volatility, expected dividend yield, remaining grant period, turnover ratio, and ratio of share price and strike price when managers voluntarily exercise ESOs. The data on the strike price, maximum exercise time, and life expectancy of ESOs are extracted from the firms' annual reports. Turnover ratios during and after the turnover rate are extracted from the 2009-2013 Corporate Salary Research Report (51job report).

The government's zero-coupon bond cannot truly reflect the term structure as China's bond market is still in its infancy. Therefore, we select an average of the one-year bank deposit rate from the date of the ESO announcement (data from the National Bureau of Statistics). Although the expected dividend yield is unknown, it generally remains stable. The average dividend yield for 2-3 years before the ESO announcement is applied in this paper and the daily volatility is annualized. The ratio of the share price and the strike price is set at 1.5 because most ESOs were implemented in 2006 and 2008 as stock prices fell in 2007. 
Previous empirical studies in the literature suggest that firms facing high risk and good growth prospects may tend to implement more ESOs. In addition, the market risk, growth prospects, different governance structures, and firm size can also affect the implementation of ESOs. Hence, the aforementioned variables are used for our regression analysis and the following model is estimated:

$$
I R_{i}=\alpha_{1}+\alpha_{2} B M_{i}+\alpha_{3} S T D R E T_{i}+\alpha_{4} R E T_{i}+\alpha_{5} O W N_{i}+\alpha_{6} C E V_{i}+\alpha_{7} S I Z E_{i}+\varepsilon_{i}
$$

Our dependent variable, denoted by $I R$, is the ratio of ESO value over firm value. The larger the value of $I R$, the higher the probability of a company implementing ESOs. The book-tomarket ratio $(B M)$ represents growth opportunities. When the value of $B M$ is less than 1, the firm is perceived to have good growth prospects. The mean of return volatility $(R E T)$ can be used to proxy the market risk. Stock price volatility (STDRET) measures corporate risk. The proportion of outstanding shares held by managers $(O W N)$, the leverage ratio $(C E V)$, and the firm size (SIZE) (data from GTA database) measure the impact of the governance structure and financial variables on the implementation of the incentive plan.

The estimation results are reported in Table 2. As shown in Table 2, the coefficients of firm size and the return volatility are positive and significant. Hence, in China, the firms with higher market risk and larger size are likely to implement more ESOs in executive incentive plans. However, the coefficients of the proportion of book-to-market ratio, the leverage ratio, the proportion of outstanding shares held by managers, and those of price volatility, are insignificant at the $5 \%$ level. This may be attributable to several reasons. First, non-tradable shares such as the 
state-owned shares have the dominant role compared with traded shares. The role of the book-tomarket and leverage ratio can be masked by these non-tradable shares in the state-owned companies. Second, there is difficulty in establishing a long-term sense of belonging between managers and a firm. As most stocks are state-owned or considered legal person shares, the amount of stock available to managers themselves is very limited. Third, managers may make investment decisions that favor an increase in stock price to ensure the value of ESOs. As a result, the share price may not truly reflect the business situation and firm risk.

\section{Conclusion}

This paper modifies the Hull \& White model by replacing historical volatility with predicted volatility. The ESOs of 83 Chinese listed companies are priced using the ESO pricing method under FAS 123 based on the SV model. The empirical analysis shows that the market risk and firm size have significant effect on the total grant value of ESOs, whereas the book-to-market ratio, stock price volatility, the executive shareholding proportion, the leverage ratio, and the market value on ESOs are shown to be insignificant in affecting the total grant value of ESOs. Therefore, large firms in China with higher market risk and larger sizes are likely to increase the proportion of ESOs in their executive incentive plans. 


\section{References}

Bollerslev, T. (1986). Generalized autoregressive conditional heteroskedasticity. Journal of Econometrics 31, 307-327.

Chen, Y. \& Lee, B. (2010). A dynamic analysis of executive stock options: determinants and consequences. Journal of Corporate Finance 16, 88-103

Choe, C. (2003). Leverage, volatility and executive stock options. Journal of Corporate Finance 9, 591-609.

Cuny, C. J. \& Jorion, P. (1995). Valuing executive stock options with endogenous departure. Journal of Accounting \& Economics 20(2), 193-205.

Duan, J. C. (1995). The GARCH option pricing model. Mathematical Finance 5, 13- 32.

Engle, R. F. (1982). Autoregressive conditional heteroskedasticity with estimates of the variance of U.K. inflation. Econometrica 50, 987-1008.

Foster, T., Koogler, P. \& Vickrey, D. (1993). Valuation of executive stock options and the FASB proposal: An extension. Accounting Review 68, 184-189.

Hull, J. \& White, A. (2002). Determining the value of employee stock options, Report Produced for the Ontario Teachers' Pension Plan.

Hull, J. \& White, A. (2003). Accounting for employee stock options. Working paper, University of Toronto.

Hull, J \& White, A. (2004). How to value employee stock options. Financial Analysts Journal 60(1), 114-119.

Jacquier, E, Polson, N.G. \& Rossi, PE. (1994). Bayesian analysis of stochastic variance models. Journal of Business \& Economic Statistics 12, 371-389.

Jennergren, L. \& Naslund, B., (1993). A comment on the valuation of executive stock options 
and the FASB proposal. Accounting Review 68, 179-183.

Joskow, P. L., Rose, N. L. \& Wolfram, C. D. (1996). Political constraints on executive compensation: Evidence from the electric utility industry. The RAND Journal of Economics 27, $165-182$.

Kim, S, Shephard, N. \& Chib, S. (1998). Stochastic volatility: likelihood inference and comparison with ARCH models. Review of Economic Studies 65, 361-393.

Li, Z. \& Huang, R. (2004). ESO pricing under GARCH framework. China Management Science $12,222-236$.

Mehran, H. (1995). Executive compensation structure, ownership, and firm performance. Journal of Financial Economics 38, 163-184.

Meyer, R. \& Yu, J. (2000). BUGS for a Bayesian analysis of stochastic volatility models. Econometrics Journal 3(2), 198-215.

Rubinstein, M. (1995). On the accounting valuation of employee stock options. Journal of Derivatives 3, 8-24.

Shephard, N. (1996). Statistical aspects of ARCH and stochastic volatility. In: Cox, D. R., Hinkley, D. V. \& Barndor-Nielson, O.E. (Eds.), Time Series Models with Econometric, Finance \& Other Applications. Chapman \& Hall, London, 1-67.

Spiegelhalter, DJ, Thomas, A, Best, NG, Lunn, D. (2003). WinBUGS User Manual. Version 1.4. Cambridge, England: MRC Biostatistics Unit.

Taylor, S. J. (1986). Modelling Financial Time Series. Chichester, England, John Wiley \& Sons, Taylor, S. J. (1994). Modelling Stochastic Volatility. Mathematical Finance 4, 183-204.

Yermack, D. (1995). Do corporations award CEO stock options effectively?. Journal of Financial Economics 39, 237-269. 
Table 1: Comparison between ESOs and ECOs

\begin{tabular}{|c|c|}
\hline cts: & \\
\hline $\begin{array}{l}\text { In the vesting period, options cannot be executed. } \\
\text { The length of time ranges from six months to three } \\
\text { years. }\end{array}$ & $\begin{array}{l}\text { If managers leave the company within the vesting } \\
\text { period, they will lose their options. If managers } \\
\text { leave the company after the vesting period, they } \\
\text { will lose out-of-money options and have to exercise } \\
\text { their options immediately. }\end{array}$ \\
\hline $\begin{array}{l}\text { ESO contract terms may be modified under certain } \\
\text { conditions. For instance, when the market price } \\
\text { falls, the company may lower the strike price of } \\
\text { options and extend the option term. Firm owners } \\
\text { will limit the number of stock holders to prevent } \\
\text { the company from falling into the hands of } \\
\text { potential acquirers. }\end{array}$ & $\begin{array}{l}\text { ESOs are non-tradable. To achieve maximum } \\
\text { returns or risk diversification, managers must } \\
\text { exercise their options or sell the underlying stock, } \\
\text { which results in earlier exercising of ESOs. After } \\
\text { the vesting period, managers can contractually } \\
\text { exercise a portion of the options in advance. } \\
\text { Therefore, ESOs are not completely European, but } \\
\text { also characterize U.S. options. }\end{array}$ \\
\hline $\begin{array}{l}\text { ESOs cannot be circulated in the market. There is } \\
\text { no transaction cost in circulation, but it is complex } \\
\text { in terms of diverse grant terms, exercise terms, tax } \\
\text { requirements, and constant changes in these terms. } \\
\text { Option costs are relatively high because listed } \\
\text { companies must also disclose relevant information. }\end{array}$ & $\begin{array}{l}\text { Stock options can be taxed either as capital gains } \\
\text { (incentive stock options) or as personal income } \\
\text { (non-incentive stock options). There is no } \\
\text { difference between incentive and non-incentive } \\
\text { stock options for firms. However, for option } \\
\text { holders, incentive stock options are more valuable } \\
\text { than non-incentive options. }\end{array}$ \\
\hline
\end{tabular}


Table 2: Regression result (Dependent Variable= IR)

\begin{tabular}{cccrr}
\hline \hline Variables & Coefficient & Std. Error & t-Statistic & p-value \\
\hline \hline BM & -0.08815 & 0.3087 & -0.2855 & 0.7760 \\
CEV & -0.00086 & 0.0714 & -0.0121 & 0.9904 \\
OWN & -0.11506 & 0.2725 & -0.4223 & 0.6740 \\
RET & 2.75026 & 1.0169 & 2.7045 & 0.0084 \\
SIZE & 1.14685 & 0.1710 & 6.7075 & 0.0000 \\
STDRET & -1.27132 & 0.8554 & -1.4863 & 0.1413 \\
C & -4.38089 & 1.0420 & -4.2043 & 0.0001 \\
\hline \hline
\end{tabular}

$\mathrm{C}$ is the intercept;

R-squared $=0.483$;

Adjusted R-squared $=0.442$. 